\title{
Diet, Lifestyles, Family History, and Prostate Cancer Incidence in an East Algerian Patient Group
}

\author{
Somia Lassed, ${ }^{1,2}$ Cláudia M. Deus, ${ }^{3}$ Nuno Lourenço, ${ }^{4}$ Abderrezak Dahdouh, ${ }^{5}$ \\ Albert A. Rizvanov, ${ }^{6}$ Paulo J. Oliveira, ${ }^{3}$ and Djamila Zama ${ }^{1}$ \\ ${ }^{1}$ Unité de recherche Valorisation des Ressources Naturelles, Molécules Bioactives et Analyses Physicochimiques et \\ Biologiques (VARENBIOMOL), Université des Frères Mentouri, Constantine, 25000 Constantine, Algeria \\ ${ }^{2}$ Laboratoire de Physiologie Animale, Département de Biologie Animale, Faculté des Sciences de la Nature et de la Vie, \\ Université des Frères Mentouri, Constantine, 25000 Constantine, Algeria \\ ${ }^{3}$ Center for Neuroscience and Cellular Biology (CNC), University of Coimbra, UC Biotech Building, Biocant Park, \\ 3060-197 Cantanhede, Portugal \\ ${ }^{4}$ Department of Informatics Engineering, Center for Informatics and Systems of University of Coimbra (CISUC), \\ Polo II-Pinhal de Marrocos, 3030 Coimbra, Portugal \\ ${ }^{5}$ Clinic of Urology-Nephrology and Kidney Transplant Daksi, 25000 Constantine, Algeria \\ ${ }^{6}$ Institute of Fundamental Medicine and Biology, Kazan Federal University, Kazan, Russia \\ Correspondence should be addressed to Djamila Zama; atrouzl@umc.edu.dz
}

Received 6 May 2016; Revised 2 September 2016; Accepted 20 September 2016

Academic Editor: Fabio Grizzi

Copyright (C) 2016 Somia Lassed et al. This is an open access article distributed under the Creative Commons Attribution License, which permits unrestricted use, distribution, and reproduction in any medium, provided the original work is properly cited.

Prostate cancer (PC) is the fourth most common cancer in men and the sixth leading cause of death in Algeria. To examine the relationship between lifestyle factors, including diet, and family history and PC risk, a case-control study was performed in an eastern Algerian population, comprising 90 patients with histologically confirmed PC and 190 controls. Data collection was carried out through a structured questionnaire and statistical analysis was performed to evaluate the different variables. The data showed that consumption of lamb and beef meat and high intake of animal fat and dairy products increased PC risk. Seven to thirteen vegetables servings per week and fourteen or more servings decreased PC risk by $62 \%$ and $96 \%$, respectively. Seven to fourteen fruit servings per week decrease PC risk by $98 \%$. Green tea consumption reduced the risk of PC but the results were statistically borderline. Increased risk was observed for individuals with family history of PC in first and in second degree. A positive strong association was also found for alcohol and smoking intake and a dose-response relationship existed for quantity and history of smoking. This study suggests that dietary habits, lifestyle factors, and family history have influence on the development of PC in Algerian population.

\section{Introduction}

After lung cancer, prostate cancer $(\mathrm{PC})$ is the most common cancer among men, with nearly a million new cases diagnosed worldwide [1]. PC incidence varies more than 25-fold worldwide; the rates are highest in Australia/New Zealand, Northern America, and Western and Northern Europe (ASR 111.6, 97.2, 94.9 and 85.0 per 100,000, resp.) and relatively high in certain regions such as the Caribbean (79.8), Southern Africa (61.8), and South America (60.1), but it is low in Asian population with estimated rates of 10.5 and 4.5 in Eastern and South-Central Asia [2]. According to GLOBOCAN 2012 database, $\mathrm{PC}$ in Algeria was the fourth most common cancer in men with 8.8 cases per 100,000 and the sixth leading cause of death with 4.9 deaths per 100,000. The incidence of PC in Algeria is considered as low when compared with some western countries such as Norway and Sweden (129.7 and 119.0 cases diagnosed and approximately 18 deaths per 100,000 , resp.), but it is still high compared to many Asian countries especially China, Korea, and Bhutan (5.3, 3.2, and 1.2 cases diagnosed and 2.5, 1.3, and 0.7 deaths per 100,000, resp.) [2]. Numerous epidemiological studies showed that 
the incidence of PC in Asian countries is low compared to the West. However, this incidence rapidly increases in Asian immigrants that have assimilated western diet and way of living, replacing soy, tea, fish, fruits, and vegetables consumption with red meat and fat-rich food [3]. Also, a study conducted in Western Australia described that the risk of PC and in particular aggressive PC increases significantly in about $80 \%$ of men who consume a western style diet [4]. The difference in PC rates may result in possible dietary, lifestyle, and environmental links to the development and progression of PC $[5,6]$. Many epidemiological and casecontrol studies disclosed that some dietary factors such as animal fat [7], dairy products [8], and red meat [9] may increase the risk of PC [7-9], whereas intake of vegetables and fruit [10], fish [11], and green tea [12] appears to be potentially protective [10-12]. The aim of this study was to examine the relationship between dietary habits, family history of PC, alcohol, and smoking and PC risk in an East Algerian population.

\section{Materials and Methods}

2.1. Data Collection. The present study was approved by the Ethics Committee of the EHS Daksi, which certified that the data collection was performed at the Department of Urology and Renal Transplant without any risk for patients. Data were derived from a case-control study of PC, performed between 2011 and 2013 in the east of Algeria. From 100 cases of histologically confirmed PC, followed at the service of urology and at the emergency department in Clinic of Urology-Nephrology and Kidney Transplant Daksi, Constantine, one patient refused to participate and 9 were too ill to be interviewed. The cohort investigated consisted of 90 patients with a median age of $68.87 \pm 0.73$, ranging from 50 to 88 years. The total Gleason score, serum PSA level at diagnosis, and primary treatment taken for each case were obtained from the medical record. Controls were men, residing in the same geographical area of cases without either PC or prostate diseases. Those with other malignancies were also excluded. Among 200 men selected, 10 refused to participate for different reasons. The final control group consisted of 190 men with a median age of $67.13 \pm 0.72$, ranging from 50 to 88 years. Sixty-one men were treated at the hospital for some urologic diseases (35 had kidney stone, 25 had urinary infection, and 10 had other diseases), 14 were men from the hospital staff invited to participate, and 115 were men selected in the blood sample collection room of the Laboratory of Biochemistry of Establishment Public Hospital of Chelghoum Laid city.

Data collection was carried out through an interview, using structured questionnaire, including information on sociodemographic characteristics, dietary habits, family history of PC, smoking, and alcohol consumption (see Supplementary Material available online at http://dx.doi.org/10.1155/ 2016/5730569). All the interviews were filled face-to-face with case and control individuals. Questionnaire on dietary habits included questions about the frequency of intake of different food items during the past years. The first item was about the number of meals per day, followed by questions about the consumption of fish and red meat (lamb and beef), by using the question "how many times per week or month," and consumption of animal fat (from red meat) or dairy products (milk, cheese, and yogurt) by using the expressions "never, small, medium or great part." In the latter, "small or medium part" of dairy products meant one cup of milk or/and some other product per day, and "great part" meant more than 2 cups of milk per day or/and a large amount of other product. Another question was related to total fruit and vegetables consumption by using the question "how many times per week. The last food-related item is regarded as green tea consumption by using the question "how many cups per day." Participants were also asked about alcohol and smoking employing the terms "non-users," "former users," and "current users." Former users were defined as those who had consumed alcoholic beverages or tobacco earlier in their life but not during the last years and current users were considered as those who actually still consume alcoholic beverages or tobacco. The total tobacco consumption was determined using pack-years unity. The original questionnaire is presented as supplementary material. All the participants were asked about their dietary habits 10 years prior to the study because the clinical PC has a long latency phase, during which the disease is histologically present and the remote dietary intake may be more important than recent dietary intake when predicting the risk of PC [13].

2.2. Statistical Analyses. The data from 90 PC cases and 190 controls were analyzed using Graph Pad Prism version 7. Firstly we started by analyzing if the samples follow a normal distribution. We relied on the Shapiro-Wilk test at a significance level of 0.05 . The results showed that the data did not follow a normal distribution so all the tests from here on will assume nothing about the distribution of the data; that is, we will rely on nonparametric tests to analyze the data. To check whether there were statistically significant differences between the control and cases groups, we used the MannWhitney test for continuous variables, such as PSA values.

The remainder of the variables (different types of food consumption, family history of PC, smoking habits, and alcoholic consumption) were grouped into categories, corresponding to the different possible answers. The individual frequency of the answers was measured and stored in a contingencies table. All tables were analyzed using the chisquare test. To compute the confidence intervals of the odds ratio (OR) we used on the Woolf logit method. $p_{\text {trend }}$ values were determined using the chi-square test for trend.

\section{Results}

The Gleason score at diagnosis was between 5 and 7 in $38 \%$ of cases and it was between 8 and 10 in $62 \%$ of cases. $12 \%$ of cases were oriented toward prostatectomy as initial treatment and $88 \%$ were oriented to start hormone therapy. There were no statistical significant differences in age between cases and controls $(p=0.101)$. Moreover, the nonparametric test Kolmogorov-Smirnov showed that the ages of the two groups (control and cases) were taken from the same distribution. The median prostate-specific antigen (PSA) level was higher 
TABLE 1: Prostate cancer cases and controls characterization.

\begin{tabular}{|c|c|c|c|}
\hline & Cases, $n(\%)$ & Controls, $n(\%)$ & $p$ value $^{\mathrm{b}}$ \\
\hline No. of subjects & 90 & 190 & \\
\hline Mean age \pm SD & $68.87 \pm 0.73^{\mathrm{a}}$ & $67.13 \pm 0.72^{\mathrm{a}}$ & 0.1012 \\
\hline Mean PSA \pm SD $(\mathrm{ng} / \mathrm{mL})$ & $122 \pm 22.04$ & $1.71 \pm 0.10$ & $<0.0001^{* * *}$ \\
\hline \multicolumn{4}{|l|}{ Gleason score } \\
\hline $5-7$ & $34(38)$ & - & - \\
\hline $8-10$ & $56(62)$ & - & - \\
\hline \multicolumn{4}{|l|}{ Primary treatment } \\
\hline Prostatectomy & $11(12)$ & - & - \\
\hline Hormone therapy & $79(88)$ & - & - \\
\hline \multicolumn{4}{|l|}{ City of living } \\
\hline Constantine & $34(38)$ & $60(32)$ & - \\
\hline Mila & $16(18)$ & $43(23)$ & - \\
\hline Guelma & $4(4)$ & $10(5)$ & - \\
\hline Setif & $5(6)$ & $12(6)$ & - \\
\hline Oum El Bouaghi & $10(11)$ & $15(8)$ & - \\
\hline Jijel & $8(9)$ & $19(10)$ & - \\
\hline Skikda & $6(7)$ & $14(7)$ & - \\
\hline Bejaia & $2(2)$ & $5(3)$ & - \\
\hline Tebassa & $3(3)$ & $8(4)$ & - \\
\hline M'Sila & $2(2)$ & $4(2)$ & - \\
\hline
\end{tabular}

${ }^{a}$ Values are expressed as mean \pm SD.

${ }^{\mathrm{b}}$ Based on Mann-Whitney; PSA: prostate-specific antigen; ${ }^{* * *} p<0.0001$.

in diseased individuals than in controls $(p<0.0001)$. All the participants were living in the same geographical area distributed by different cities in the east of Algeria (Table 1).

Table 2 shows the odds ratio and the relative risk for the relationship between the intake of different food items and PC. When comparing men who ate more than three meals per day to men who consumed only two to three meals per day, no statistically significant associations were observed between numbers of meals consumed per day and PC risk. Also, no statistical association was found between fish consumption and PC, when comparing men who ate fish more than three times per month to those who had fish in their meals less than 2 times per month. A significant relationship between red meat consumption and $\mathrm{PC}$ risk was observed. A strong positive association $(p<0.0001)$ between lamb consumption and PC was found. The odds ratio and the relative risk increased significantly with the increased lamb meat meals consumed per month. Compared to those who never or rarely consumed lamb, they were, respectively, 3.33 (1.74 to 6.37) and 2.46 (1.49 to 4.06), $p=0.0002$, in those who consumed lamb between one to two times per month and were 4.99 (2.36 to 10.53) and 3.10 (1.84 to 5.24), $p<0.0001$, in those who consumed lamb three times or more per month. A positive association was also found between beef consumption and PC $\left(p_{\text {trend }}=0.013\right)$, but it was only significant in men who ate beef three times or more per month. Concerning animal fat derived from red meat consumption, a strong positive correlation was found $\left(p_{\text {trend }}<0.0001\right)$. Increased risk was observed for men with high intake of animal fat compared to those who never eat animal fat or just normally consumed a small part relative to the total of food intake daily [OR 7.38 (95\% CI 3.87 to $14.06)$ and RR 3.02 (95\% CI 2.17 to 4.20 ); $p<0.0001$ ]. The dairy product intake was also associated with PC risk. The risk increased significantly in men with high intake of dairy products compared to those who consumed just a small or medium part daily. Inverse strong association was observed between total fruit and total vegetables consumption and PC risk ( $\left.p_{\text {trend }}<0.0001\right)$. The odds ratio and the relative risk decreased significantly with increased fruit and vegetables consumed per week. The results obtained showed that PC is less common in men who consumed vegetables 7 to 13 times per week and much less common for those who intake vegetables 14 or more times per week and fruit 7 to 14 times per week. Results concerning green tea consumption showed that PC risk decreased with the number of cups of green tea consumed per day. However, these results were not significant $\left(p_{\text {trend }}=0.07\right)$, and OR and RR were, respectively, $0.64(95 \%$ CI 0.36 to 1.15 ) and 0.74 (95\% CI 0.48 to 1.12), $p=0.1569$, for those who drank 1 to 3 cups per day, and they were 0.40 (95\% CI 0.08 to 1.92 ) and 0.51 (95\% CI 0.14 to 1.82 ), $p=0.2025$, for individuals who had consumption of more than 3 cups per day.

The results in Table 3 indicate that a higher proportion of cases had a family history of PC (22\%) compared to controls (4\%). A statistically significant association between family history of PC in first degree (father or brother) and PC risk was observed. Men with a family history of $\mathrm{PC}$ in second degree (grandfather or uncle) were also at higher risk of getting PC. A positive strong correlation was observed between PC incidence and alcohol consumption $(p<0.0001)$. The odds ratio and the relative risk for former users compared to nonusers were, respectively, 5.53 (95\% CI 2.68 to 11.42 ) and 2.51 (95\% CI 1.84 to 3.40). Also, smoking status showed a potent positive association between smoking and the risk of getting PC $\left(p_{\text {trend }}<0.0001\right)$. The odds ratio and relative risk for former smokers compared to nonsmokers were, respectively, 3.17 (95\% CI 1.76 to 5.69 ) and 2.27 (95\% CI 1.47 to 3.50 ) and, for current smokers, the values were, respectively, 4.05 (95\% CI 1.84 to 8.89 ) and 2.60 (95\% CI 1.57 to 4.31). According to total tobacco consumption, we found a dose-response relation to PC risk which was 3.56 -fold higher in men who consumed more than forty pack-years (more than $292 \mathrm{~kg}$ of tobacco) in their life (Table 3).

\section{Discussion}

In this study, controls and PC-positive patients were collected in the same period and interviewed face-to-face using a structured questionnaire to decrease the probability of bias. Cases were interviewed only after the confirmation of their disease and controls were selected carefully and matched to disease cases based on age and region of residence. The use of past 10 years' dietary history is justified by the fact that $\mathrm{PC}$ has a long latency period (10 to 15 years) [13] and because dietary changes may have occurred after diagnosis of the disease, thus not reflecting the typical diet consumed before the onset of PC. Still, since this is a case-control study we cannot exclude a certain degree of recall bias [14]. 
TABLE 2: Association between the amount and kind of different food items and the risk of prostate cancer.

\begin{tabular}{|c|c|c|c|c|c|c|c|}
\hline & Cases, $n(\%)$ & Controls, $n(\%)$ & Odds ratio $^{a}$ & $95 \% \mathrm{CI}^{\mathrm{a}}$ & Relative risk $^{\mathrm{a}}$ & $95 \% \mathrm{CI}^{\mathrm{a}}$ & $p$ value $^{\mathrm{a}}$ \\
\hline \multicolumn{8}{|l|}{ Number of meals/day } \\
\hline 2 to 3 meals & $70(78)$ & $158(83)$ & 1 & & & & \\
\hline$>3$ meals & $20(22)$ & $32(17)$ & 1.41 & $0.75-2.63$ & 1.25 & $0.84-1.86$ & 0.3238 \\
\hline \multicolumn{8}{|l|}{ Fish, time/month } \\
\hline $0-2$ & $55(61)$ & $118(62)$ & 1 & & & & \\
\hline$\geq 3$ & $35(39)$ & $72(38)$ & 1.04 & $0.62-1.74$ & 1.03 & $0.72-1.45$ & 0.8957 \\
\hline \multicolumn{8}{|l|}{ Red meat, time/month } \\
\hline \multicolumn{8}{|l|}{ Lamb } \\
\hline 0 & $17(19)$ & $95(50)$ & 1 & & & & \\
\hline $1-2$ & $40(44)$ & $67(35)$ & 3.33 & $1.74-6.37$ & 2.46 & $1.49-4.06$ & $0.0002^{* * *}$ \\
\hline$\geq 3$ & $25(28)$ & $28(15)$ & 4.99 & $2.36-10.53$ & 3.10 & $1.84-5.24$ & $<0.0001^{* * * *}$ \\
\hline$p_{\text {trend }}^{\mathrm{b}}$ & & & $<0.0001^{* * * *}$ & & & & \\
\hline \multicolumn{8}{|l|}{ Beef } \\
\hline 0 & $16(18)$ & $57(30)$ & 1 & & & & \\
\hline $1-2$ & $39(43)$ & $81(43)$ & 1.71 & $0.87-3.36$ & 1.48 & $0.89-2.45$ & 0.1394 \\
\hline$\geq 3$ & $35(39)$ & $52(27)$ & 2.39 & $1.19-4.83$ & 1.83 & $1.11-3.03$ & $0.0170^{*}$ \\
\hline$p_{\text {trend }} \mathrm{b}$ & & & $0.013^{*}$ & & & & \\
\hline \multicolumn{8}{|l|}{ Animal fat } \\
\hline Never or small part ${ }^{1}$ & $37(41)$ & $127(67)$ & 1 & & & & \\
\hline Medium part ${ }^{1}$ & $10(11)$ & $43(23)$ & 0.79 & $0.36-1.74$ & 0.83 & $0.44-1.56$ & 0.7020 \\
\hline Great part $^{1}$ & $43(48)$ & $20(10)$ & 7.38 & $3.87-14.06$ & 3.02 & $2.17-4.20$ & $<0.0001^{* * * *}$ \\
\hline$p_{\text {trend }}^{\mathrm{b}}$ & & & $<0.0001^{* * * *}$ & & & & \\
\hline \multicolumn{8}{|l|}{ Dairy product } \\
\hline Small or medium part ${ }^{2}$ & $45(50)$ & $144(76)$ & 1 & & & & \\
\hline Great part ${ }^{3}$ & $45(50)$ & $46(24)$ & 3.13 & $1.84-5.31$ & 2.07 & $1.49-2.88$ & $<0.0001^{* * * *}$ \\
\hline \multicolumn{8}{|l|}{ Total fruit, time/week } \\
\hline$<2$ & $17(19)$ & $4(2)$ & 1 & & & & \\
\hline $2-6$ & $59(66)$ & $34(18)$ & 0.40 & $0.12-1.31$ & 0.78 & $0.60-1.01$ & 0.198 \\
\hline $7-14$ & $14(15)$ & $152(80)$ & 0.02 & $0.00-0.07$ & 0.10 & $0.06-0.17$ & $<0.0001^{* * * *}$ \\
\hline$p_{\text {trend }} \mathrm{b}$ & & & $<0.0001^{* * * *}$ & & & & \\
\hline \multicolumn{8}{|l|}{ Total vegetables, time/week } \\
\hline$<7$ & $18(20)$ & $7(4)$ & 1 & & & & \\
\hline $7-13$ & $60(67)$ & $61(32)$ & 0.38 & $0.14-0.98$ & 0.68 & $0.50-0.93$ & $0.048^{*}$ \\
\hline$\geq 14$ & $12(13)$ & $122(64)$ & 0.03 & $0.01-0.10$ & 0.12 & $0.06-0.22$ & $<0.0001^{* * * *}$ \\
\hline$p_{\text {trend }}^{\mathrm{b}}$ & & & $<0.0001^{* * * *}$ & & & & \\
\hline \multicolumn{8}{|c|}{ Green tea consumption, cups/day } \\
\hline$<1$ & $67(75)$ & $122(64)$ & 1 & & & & \\
\hline $1-3$ & $21(23)$ & $59(31)$ & 0.64 & $0.36-1.15$ & 0.74 & $0.48-1.12$ & 0.1569 \\
\hline$>3$ & $2(2)$ & $9(5)$ & 0.40 & $0.08-1.92$ & 0.51 & $0.14-1.82$ & 0.2025 \\
\hline$p_{\text {trend }}^{\mathrm{b}}$ & & & 0.07 & & & & \\
\hline
\end{tabular}

$95 \% \mathrm{CI}=95 \%$ confidence interval. ${ }^{\mathrm{a}}$ Determined using the chi-square test. ${ }^{\mathrm{b}}$ Determined using the chi-square test for trend; ${ }^{*} p<0.05,{ }^{* * *} p<0.005$, and **** $p<0.0001$.

${ }^{1}$ Relative to the total of daily food intake. ${ }^{2}$ One cup of milk or/with some other product (cheese, yogurt) per day. ${ }^{3}$ More than 2 cups of milk per day or/with a big quantity of other product (cheese, yogurt).

The number of meals taken per day, which can be an indicator of total energy intake, showed no association with the risk of PC in this study. Theoretically, high energy intake can play a relevant role in several neoplasms since it may stimulate the sympathetic nervous system and basal metabolism leading to increased IGF-1 release which increases cell proliferation automatically through the stimulation of mitosis [15].
Several case-control studies reported an association [16-18] or no association $[19,20]$ between increased PC risk and high energy intake.

Numerous epidemiological studies examined the relationship between fish consumption and PC. Although many suggested risk reduction associated with high intake, others are contradictory. A follow-up of 47,882 men during 12 years 
TABLE 3: Association between family history of prostate cancer, alcohol consumption, and smoking habits and the risk of prostate cancer.

\begin{tabular}{|c|c|c|c|c|c|c|c|}
\hline & Cases, $n(\%)$ & Controls, $n(\%)$ & Odds ratio $^{a}$ & $95 \% \mathrm{CI}^{\mathrm{a}}$ & Relative risk $^{\mathrm{a}}$ & $95 \% \mathrm{CI}^{\mathrm{a}}$ & $p$ value $^{\mathrm{a}}$ \\
\hline \multicolumn{8}{|c|}{ Family history of prostate cancer } \\
\hline Absent & $70(78)$ & $182(96)$ & 1 & & & & \\
\hline In first degree & $11(12)$ & $3(1)$ & 9.53 & $2.58-35.20$ & 2.82 & $2.01-3.96$ & $0.0002^{* * *}$ \\
\hline In second degree & $9(10)$ & $5(3)$ & 4.68 & $1.51-14.45$ & 2.31 & $1.49-3.58$ & $0.0063^{* *}$ \\
\hline$p_{\text {trend }}^{\mathrm{b}}$ & & & $<0.0001^{* * * *}$ & & & & \\
\hline \multicolumn{8}{|l|}{ Alcohol status } \\
\hline Nonusers & $64(71)$ & $177(93)$ & 1 & & & & \\
\hline Former users & $26(29)$ & $13(7)$ & 5.53 & $2.68-11.42$ & 2.51 & $1.84-3.40$ & $<0.0001^{* * * *}$ \\
\hline \multicolumn{8}{|l|}{ Smoking status } \\
\hline Nonsmokers & $22(24)$ & $99(52)$ & 1 & & & & \\
\hline Former smokers & $50(56)$ & $71(37)$ & 3.17 & $1.76-5.69$ & 2.27 & $1.47-3.50$ & $0.0001^{* * *}$ \\
\hline Current smokers & $18(20)$ & $20(11)$ & 4.05 & $1.84-8.89$ & 2.60 & $1.57-4.31$ & $0.0006^{* * *}$ \\
\hline$p_{\text {trend }}^{\mathrm{b}}$ & & & $<0.0001^{* * * *}$ & & & & \\
\hline \multicolumn{8}{|c|}{ Total tobacco consumption, unity of pack-years } \\
\hline 0 & $22(24)$ & $99(52)$ & 1 & & & & \\
\hline $1-9$ & $9(10)$ & $20(11)$ & 2.02 & $0.81-5.04$ & 1.70 & $0.88-3.30$ & 0.1326 \\
\hline $10-19$ & $15(17)$ & $27(14)$ & 2.50 & $1.14-5.46$ & 1.96 & $1.12-3.42$ & $0.0311^{*}$ \\
\hline $20-29$ & $11(12)$ & $23(12)$ & 2.15 & $0.91-5.05$ & 1.78 & $0.96-3.29$ & 0.0964 \\
\hline $30-39$ & $9(10)$ & $8(4)$ & 5.06 & $1.75-14.59$ & 2.91 & $1.62-5.23$ & $0.0033^{* *}$ \\
\hline$\geq 40$ & $24(27)$ & $13(7)$ & 8.30 & $3.66-18.83$ & 3.56 & $2.28-5.57$ & $<0.0001^{* * * *}$ \\
\hline$p_{\text {trend }}{ }^{\mathrm{b}}$ & & & $<0.0001^{* * * *}$ & & & & \\
\hline
\end{tabular}

$95 \% \mathrm{CI}=95 \%$ confidence interval. ${ }^{\mathrm{a}}$ Determined using the chi-square test. ${ }^{\mathrm{b}}$ Determined using the chi-square test for trend; ${ }^{*} p<0.05,{ }^{* *} p<0.01,{ }^{* * *} p<$ 0.005 , and ${ }^{* * * *} p<0.0001$.

in the Health Professionals Study found that the consumption of more than three times per week of fish was associated with a reduced risk of PC. The strongest association was found for metastatic cancer (RR 0.56 ; $95 \%$ CI 0.37 to 0.86 , compared with infrequent consumption, i.e., less than twice per month) [11]. Similarly, five or more servings of fish per week versus less than once was associated with a significant reduction in PC risk [21]. Also, a recent study suggested that prostate tissue $\omega-3$ fatty acids, especially eicosapentaenoic acid (EPA), are protective against PC progression in men with low risk for that disease [22]. However a meta-analysis study provided no strong evidence of a protective association of fish consumption with PC incidence [23]. No association was observed in our study between fish consumption and PC, which may be explained by the low levels of fish consumption, compared to other studies cited [11, 21].

Our study showed a strong association between red meat and high animal fat consumption and PC. Several previous studies examined the relationship between red meat and PC risk with conflicting results. Some studies suggested a positive association $[9,24,25]$, whereas others have found no association $[26,27]$. Among studies which suggested a positive association, a case-control study found that eating red meat (beef, lamb, or pork) at least 5 times per week increased the risk of PC incidence by 2.5 -fold [9], which was confirmed by further studies [24]. The increased risk may stem from triggering of carcinogenesis by high fat content, formation of carcinogenic heterocyclic amines (HCAs) during cooking at high temperature, carcinogenic N-nitroso compounds (NOCs), and the promotion of carcinogenesis by heme iron $[25,26]$, although infection by tumorigenic pathogens has been increasingly denoted as possible cause [28]. Animal fat was positively associated with PC risk in this study, in line with previous works $[7,29,30]$ but not others $[31,32]$. The prospective cohort study of Giovannucci et al. concluded that red meat and total fat consumption was directly related to the risk of advanced PC and the association of the latter was primarily due to animal fat. However, fat from dairy products (with the exception of butter) or fish was unrelated to the risk of PC [7]. Also in a prospective study, men in the lower tercile of saturated fat consumption compared to those in the upper tercile had three times the risk of dying from PC [29]. The link between dietary fat content and the development of PC is possibly related to the increase in sex hormone and IGF-1 concentration [33], alteration of cell membrane function, and modulation of metabolic processes [34] or to increased oxygen radicals generation [35].

Total dairy product intake was also positively associated with the risk of PC in this study. The relationship between PC and dairy products showed significant positive association $[8,36,37]$, overall null association $[38,39]$, or an inverse association [40]. In the epidemiologic follow-up study, results were similar to ours, showing that men in the highest tercile for dairy food intake had a relative risk of 2.2 (95\% CI 1.2 to $3.9 ; p_{\text {trend }}=0.05$ ) compared with men in the lowest tercile [8]. However, in the majority of other studies the relative risk was lower, 1.63 (95\% CI 1.14 to 2.32$)$ and $p_{\text {trend }}=$ 
0.01 , in a population based prospective study performed with 43,435 Japanese men [36] and 1.26 (95\% CI 1.04 to 1.51) and $p_{\text {trend }}=0.03$ in a large prospective study from Finland [37]. Several potential mechanisms explain the relationship between dairy product intake and the increased PC risk. First, the high level of calcium or phosphate content in plasma may lower intracellular bioactive metabolite of vitamin $D$, 1,25 dihydroxycholecalciferol concentration, [41] which is described to have an antiproliferative effect [42]. Second, higher intake of milk and calcium has been associated with increased plasma levels of IGF-1 [43]. Third, estrogen content in milk has been suggested also as possible explanation [44].

Among all food items studied, our study showed that total vegetables and fruit consumption presented a statistically significant protective effect on PC. These results support that high consumption of vegetables and fruit are associated with decreased risk of PC and are in agreement with the findings of a case-control study performed in Montevideo [10]. Nevertheless the finding in this context remains contradictory. Some studies suggested that total fruit or vegetable consumption may not exert a protective role [24, 45]. However, in another study a large fruit intake was associated with increased risk of PC [46].

Green tea polyphenols, especially catechins, inhibit carcinogenesis by different mechanisms [47] and in the majority of epidemiological studies a significant decrease in the risk of PC incidence was observed with increasing intake of green tea. In a case-control study in Southeast China, a consumption of 3 cups of green tea daily lowered the risk of PC [12]. In a large cohort study in Japan, only 5 or more cups per day reduced the risk of advanced PC [48]. Agreeing with some studies $[49,50]$, our results did not confirm the protective effect of green tea consumption. This can be explained by the fact that green tea is not a popular beverage in Algeria. The studied population reflected the fact that most of the studied individuals rarely or never drink green tea.

The family history of PC was another factor risk in the Algerian population studied. $22 \%$ of PC cases had a family history of PC, against only $4 \%$ of controls. Family history of PC has been examined in many studies and in different populations, with most studies finding a positive association [51-53]. Steinberg et al. observed increased PC risk among men whose first or second degree relatives also had PC [52]. In a multicenter case-control study performed in the US and Canada in Afro-American, Whites, and Asian-Americans, $13 \%$ of cases and $5 \%$ of controls reported a father, brother, or son with PC and family history association with a statistically significant 2- to 3-fold increase in risk in each of the three ethnic groups [53]. Also, in a recent study in Brazil, family history was also a PC risk factor [51]. In addition to the positive association found between family history and PC risk, the latter increased with the number of relatives affected [52].

Our results suggest that alcohol intake is associated with increased PC risk. No current users were found in the population studied since cases and control individuals never drink alcohol or just drank a few times during their youth, with the rest (29\% cases and $7 \%$ controls) being former users. Most studies showed no association between alcohol intake and PC [54-56] with a few studies reporting an inverse association [57, 58]. In a follow-up study of alcohol and PC, a significant inverse association was shown between distant past heavy drinking ( 25 drinks/week) and PC [58]. Similarly, an inverse association was observed in another study with the total number of drinking years but no association was found with lifetime intake of total and beverage specific ethanol [57]. In these studies, the protective role of alcohol observed has been interpreted by the finding that alcohol may increase metabolic clearance of testosterone [59]. Nevertheless, our study is comparable with many others supporting the hypothesis that alcohol increases PC risk. In a recent case-control study, current alcohol intake was not associated with PC but lifetime intake increased significantly the risk of both aggressive and nonaggressive PC [60] while, in the cohort of US health professionals, men who drank large amounts of alcohol in a short time were also found to be at higher risk of PC [61]. Other studies suggested that heavy alcohol consumers or alcohol abusers have higher PC incidence, with 4 alcoholic drinks per day being associated with about a $21 \%$ increased risk of PC [62]. In our study, we did not have enough information from all cases and controls to examine the association between the amount and the period of alcohol intake and PC risk.

In contrast to several studies which did not support that smoking is a factor risk of PC $[17,24,55]$, we found out that smoking was associated with increased risk. Our results support the finding of other studies which found a positive association between smoking and PC risk. In the study of Plaskon et al. current smokers were associated with an increased risk in contrast to former smokers, with a dose-response relation noted between number of pack-years smoked and PC risk [63]. In another study, the relative risk for PC was significantly elevated among cigarette smokers but no clear dose-response relation for was observed [64]. Another study found that early (before age 30), late (within recent 10 years), and lifetime cumulative smoking history were unrelated to the risk of total PC. While men who had smoked 15 or more pack-years of cigarettes within the preceding 10 years were at higher risk of distant metastatic and fatal PC, the excess risk among smokers was eliminated after 10 years of quitting [65]. Two pathogenic mechanisms were proposed to link cigarette smoking and increased PC risk. The first one is related to carcinogenic substances found in cigarettes such as cadmium which can indirectly induce PC through the interaction with androgen receptor [66]. A second factor relates to the effect of smoking on sex hormones level. Male smokers are reported to have elevated level of circulating testosterone [67].

\section{Conclusion}

Our study indicates that dietary habits, family history of PC, alcohol intake, and smoking may influence the development of PC in East Algerian population. Risk factors for PC appeared to be the intake of red meat, high consumption of animal fat and dairy product, family history of PC, alcohol intake, and smoking. A protective effect was found for high intake of fruit and vegetables. Green tea reduced, although 
not statistically significant, the risk of PC. However the number of meals intake per day and fish consumption was found to be independent factors for PC.

\section{Competing Interests}

The authors declare that they have no conflict of interests.

\section{Authors' Contributions}

Somia Lassed performed research study, collected and analyzed the data, and wrote the manuscript. Cláudia M. Deus, Albert A. Rizvanov, Nuno Lourenço, and Paulo J. Oliveira analyzed the data and revised the manuscript. Abderrezak Dahdouh and Djamila Zama designed and supervised the study and revised the manuscript.

\section{Acknowledgments}

This study was supported financially by an individual Project (F0092012009) and research unit programmatic funding (VARENBIOMOL) at Constantine University, Algeria. The authors are grateful to all the staff of Clinic of UrologyNephrology and Kidney Transplant in Daksi, Constantine, Algeria, and the staff at the Laboratory of Biochemistry of Establishment Public Hospital of Chelghoum Laid for their cooperation and valuable assistance.

\section{References}

[1] M. M. Center, A. Jemal, J. Lortet-Tieulent et al., "International variation in prostate cancer incidence and mortality rates," European Urology, vol. 61, no. 6, pp. 1079-1092, 2012.

[2] J. Ferlay, I. Soerjomataram, M. Ervik et al., GLOBOCAN 2012 v1.0, Cancer Incidence and Mortality Worldwide, IARC Cancer Base No. 11, International Agency for Research on Cancer, Lyon, France, 2012, http://globocan.iarc.fr.

[3] M. Namiki, H. Akaza, S. E. Lee et al., "Prostate cancer working group report," Japanese Journal of Clinical Oncology, vol. 40, supplement 1, Article ID hyq130, pp. i70-i75, 2010.

[4] G. L. Ambrosini, L. Fritschi, N. H. de Klerk, D. Mackerras, and J. Leavy, "Dietary patterns identified using factor analysis and prostate cancer risk: a case control study in Western Australia," Annals of Epidemiology, vol. 18, no. 5, pp. 364-370, 2008.

[5] A. W. Hsing, L. Tsao, and S. S. Devesa, "International trends and patterns of prostate cancer incidence and mortality," International Journal of Cancer, vol. 85, no. 1, pp. 60-67, 2000.

[6] A. Wolk, "Diet, lifestyle and risk of prostate cancer," Acta Oncologica, vol. 44, no. 3, pp. 277-281, 2005.

[7] E. Giovannucci, E. B. Rimm, G. A. Colditz et al., "A prospective study of dietary fat and risk of prostate cancer," Journal of the National Cancer Institute, vol. 85, no. 19, pp. 1571-1579, 1993.

[8] M. Tseng, R. A. Breslow, B. I. Graubard, and R. G. Ziegler, "Dairy, calcium, and vitamin D intakes and prostate cancer risk in the National Health and Nutrition Examination Epidemiologic Follow-up Study cohort," American Journal of Clinical Nutrition, vol. 81, no. 5, pp. 1147-1154, 2005.

[9] P. H. Gann, C. H. Hennekens, F. M. Sacks, F. Grodstein, E. L. Giovannucci, and M. J. Stampfer, "Prospective study of plasma fatty acids and risk of prostate cancer," Journal of the National Cancer Institute, vol. 86, no. 4, pp. 281-286, 1994.

[10] H. Deneo-Pellegrini, E. De Stefani, A. Ronco, and M. Mendilaharsu, "Foods, nutrients and prostate cancer: a case-control study in Uruguay," British Journal of Cancer, vol. 80, no. 3-4, pp. 591-597, 1999.

[11] K. Augustsson, D. S. Michaud, E. B. Rimm et al., "A prospective study of intake of fish and marine fatty acids and prostate cancer," Cancer Epidemiology Biomarkers and Prevention, vol. 12, no. 1, pp. 64-67, 2003.

[12] L. Jian, L. P. Xie, A. H. Lee, and C. W. Binns, "Protective effect of green tea against prostate cancer: a case-control study in southeast China," International Journal of Cancer, vol. 108, no. 1, pp. 130-135, 2004.

[13] G. Soos, I. Tsakiris, J. Szanto, C. Turzo, P. G. Haas, and B. Dezso, "The prevalence of prostate carcinoma and its precursor in Hungary: an autopsy study," European Urology, vol. 48, no. 5, pp. 739-744, 2005.

[14] L. N. Kolonel, A. M. Y. Nomura, and R. V. Cooney, "Dietary fat and prostate cancer: current status," Journal of the National Cancer Institute, vol. 91, no. 5, pp. 414-428, 1999.

[15] S. E. Dunn, F. W. Kari, J. French et al., "Dietary restriction reduces insulin-like growth factor I levels, which modulates apoptosis, cell proliferation, and tumor progression in p53deficient mice," Cancer Research, vol. 57, no. 21, pp. 4667-4672, 1997.

[16] S.-O. Andersson, A. Wolk, R. Bergström et al., "Energy, nutrient intake and prostate cancer risk: a population-based case-control study in Sweden," International Journal of Cancer, vol. 68, no. 6, pp. 716-722, 1996.

[17] H. Grönberg, L. Damber, and J.-E. Damber, "Total food consumption and body mass index in relation to prostate cancer risk: a case-control study in Sweden with prospectively collected exposure data," Journal of Urology, vol. 155, no. 3, pp. 969-974, 1996.

[18] E. L. Richman, S. A. Kenfield, J. E. Chavarro et al., "Fat intake after diagnosis and risk of lethal prostate cancer and all-cause mortality," JAMA Internal Medicine, vol. 173, no. 14, pp. 13181326, 2013.

[19] P. Ghadirian, A. Lacroix, P. Maisonneuve et al., "Nutritional factors and prostate cancer: a case-control study of French Canadians in Montreal, Canada," Cancer Causes and Control, vol. 7, no. 4, pp. 428-436, 1996.

[20] A. G. Schuurman, P. A. van den Brandt, E. Dorant, H. A. M. Brants, and R. A. Goldbohm, "Association of energy and fat intake with prostate carcinoma risk: results from the Netherlands Cohort Study," Cancer, vol. 86, no. 6, pp. 1019-1027, 1999.

[21] J. E. Chavarro, M. J. Stampfer, M. N. Hall, H. D. Sesso, and J. Ma, "A 22-y prospective study of fish intake in relation to prostate cancer incidence and mortality," The American Journal of Clinical Nutrition, vol. 88, no. 5, pp. 1297-1303, 2008.

[22] X. Moreel, J. Allaire, C. Léger et al., "Prostatic and dietary omega-3 fatty acids and prostate cancer progression during active surveillance," Cancer Prevention Research, vol. 7, no. 7, pp. 766-776, 2014.

[23] K. M. Szymanski, D. C. Wheeler, and L. A. Mucci, "Fish consumption and prostate cancer risk: a review and metaanalysis," The American Journal of Clinical Nutrition, vol. 92, no. 5, pp. 1223-1233, 2010.

[24] L. Le Marchand, L. N. Kolonel, L. R. Wilkens, B. C. Myers, and T. Hirohata, "Animal fat consumption and prostate cancer: 
a prospective study in hawaii," Epidemiology, vol. 5, no. 3, pp. 276-282, 1994.

[25] R. Sinha, Y. Park, B. I. Graubard et al., "Meat and meatrelated compounds and risk of prostate cancer in a large prospective cohort study in the United States," American Journal of Epidemiology, vol. 170, no. 9, pp. 1165-1177, 2009.

[26] A. J. Cross, U. Peters, V. A. Kirsh et al., "A prospective study of meat and meat mutagens and prostate cancer risk," Cancer Research, vol. 65, no. 24, pp. 11779-11784, 2005.

[27] D. S. Michaud, K. Augustsson, E. B. Rimm, M. J. Stampfer, W. C. Willet, and E. Giovannucci, "A prospective study on intake of animal products and risk of prostate cancer," Cancer Causes and Control, vol. 12, no. 6, pp. 557-567, 2001.

[28] H. zur Hausen, "Red meat consumption and cancer: reasons to suspect involvement of bovine infectious factors in colorectal cancer," International Journal of Cancer, vol. 130, no. 11, pp. 2475-2483, 2012.

[29] Y. Fradet, F. Meyer, I. Bairati, R. Shadmani, and L. Moore, "Dietary fat and prostate cancer progression and survival," European Urology, vol. 35, no. 5-6, pp. 388-391, 1999.

[30] S. Koutros, A. J. Cross, D. P. Sandler et al., "Meat and meat mutagens and risk of prostate cancer in the agricultural health study," Cancer Epidemiology, Biomarkers \& Prevention, vol. 17, no. 1, pp. 80-87, 2008.

[31] S.-Y. Park, S. P. Murphy, L. R. Wilkens, B. E. Henderson, and L. N. Kolonel, "Fat and meat intake and prostate cancer risk: the Multiethnic Cohort Study," International Journal of Cancer, vol. 121, no. 6, pp. 1339-1345, 2007.

[32] P. Wallström, A. Bjartell, B. Gullberg, H. Olsson, and E. Wirfält, "A prospective study on dietary fat and incidence of prostate cancer (Malmö, Sweden)," Cancer Causes and Control, vol. 18, no. 10, pp. 1107-1121, 2007.

[33] R. J. Barnard, T. H. Ngo, P.-S. Leung, W. J. Aronson, and L. A. Golding, "A low-fat diet and/or strenuous exercise alters the IGF axis in vivo and reduces prostate tumor cell growth in vitro," Prostate, vol. 56, no. 3, pp. 201-206, 2003.

[34] A. Comba, Y.-H. Lin, A. R. Eynard, M. A. Valentich, M. E. Fernandez-Zapico, and M. E. Pasqualini, "Basic aspects of tumor cell fatty acid-regulated signaling and transcription factors," Cancer and Metastasis Reviews, vol. 30, no. 3-4, pp. 325342, 2011.

[35] M. Tada, E. Ichiishi, R. Saito, N. Emoto, Y. Niwano, and M. Kohno, "Myristic acid, a side chain of phorbol myristate acetate (PMA), can activate human polymorphonuclear leukocytes to produce oxygen radicals more potently than PMA," Journal of Clinical Biochemistry and Nutrition, vol. 45, no. 3, pp. 309-314, 2009.

[36] N. Kurahashi, M. Inoue, M. Iwasaki, S. Sasazuki, and S. Tsugane, "Dairy product, saturated fatty acid, and calcium intake and prostate cancer in a prospective cohort of Japanese men," Cancer Epidemiology Biomarkers and Prevention, vol. 17, no. 4, pp. 930937, 2008.

[37] P. N. Mitrou, D. Albanes, S. J. Weinstein et al., "A prospective study of dietary calcium, dairy products and prostate cancer risk (Finland)," International Journal of Cancer, vol. 120, no. 11, pp. 2466-2473, 2007.

[38] M. Huncharek, J. Muscat, and B. Kupelnick, "Dairy products, dietary calcium and vitamin $\mathrm{D}$ intake as risk factors for prostate cancer: a meta-analysis of 26,769 cases from 45 observational studies," Nutrition and Cancer, vol. 60, no. 4, pp. 421-441, 2008.
[39] K. A. Koh, H. D. Sesso, R. S. Paffenbarger Jr., and I.-M. Lee, "Dairy products, calcium and prostate cancer risk," British Journal of Cancer, vol. 95, no. 11, pp. 1582-1585, 2006.

[40] H. D. Vlajinac, J. M. Marinković, M. D. Ilić, and N. I. Kocev, "Diet and prostate cancer: a case-control study," European Journal of Cancer-Part A, vol. 33, no. 1, pp. 101-107, 1997.

[41] E. Giovannucci, "Dietary influences of $1,25(\mathrm{OH})_{2}$ vitamin D in relation to prostate cancer: a hypothesis," Cancer Causes and Control, vol. 9, no. 6, pp. 567-582, 1998.

[42] S. E. Blutt, T. J. McDonnell, T. C. Polek, and N. L. Weigel, "Calcitriol-induced apoptosis in LNCaP cells is blocked by overexpression of Bcl-2," Endocrinology, vol. 141, no. 1, pp. 10$17,2000$.

[43] D. Gunnell, S. E. Oliver, T. J. Peters et al., "Are diet-prostate cancer associations mediated by the IGF axis? A cross-sectional analysis of diet, IGF-1 and IGFBP-3 in healthy middle-aged men," British Journal of Cancer, vol. 88, no. 11, pp. 1682-1686, 2003.

[44] L.-Q. Qin, P.-Y. Wang, T. Kaneko, K. Hoshi, and A. Sato, "Estrogen: one of the risk factors in milk for prostate cancer," Medical Hypotheses, vol. 62, no. 1, pp. 133-142, 2004.

[45] H. Meng, W. Hu, Z. Chen, and Y. Shen, "Fruit and vegetable intake and prostate cancer risk: a meta-analysis," Asia-Pacific Journal of Clinical Oncology, vol. 10, no. 2, pp. 133-140, 2014.

[46] A. G. Schuurman, R. A. Goldbohm, E. Dorant, and P. A. van den Brandt, "Vegetable and fruit consumption and prostate cancer risk: a cohort study in the Netherlands," Cancer Epidemiology Biomarkers and Prevention, vol. 7, no. 8, pp. 673-680, 1998.

[47] C. E. Harper, B. B. Patel, J. Wang, I. A. Eltoum, and C. A. Lamartiniere, "Epigallocatechin-3-gallate suppresses early stage, but not late stage prostate cancer inTRAMP mice: mechanisms of action," Prostate, vol. 67, no. 14, pp. 1576-1589, 2007.

[48] N. Kurahashi, S. Sasazuki, M. Iwasaki, and M. Inoue, "Green tea consumption and prostate cancer risk in Japanese men: A Prospective Study," American Journal of Epidemiology, vol. 167, no. 1, pp. 71-77, 2008.

[49] N. E. Allen, C. Sauvaget, A. W. Roddam et al., "A prospective study of diet and prostate cancer in Japanese men," Cancer Causes and Control, vol. 15, no. 9, pp. 911-920, 2004.

[50] N. Kikuchi, K. Ohmori, T. Shimazu et al., "No association between green tea and prostate cancer risk in Japanese men: the Ohsaki Cohort Study," British Journal of Cancer, vol. 95, no. 3, pp. 371-373, 2006.

[51] R. L. Muller, E. F. Faria, G. F. Carvalhal et al., "Association between family history of prostate cancer and positive biopsies in a Brazilian screening program," World Journal of Urology, vol. 31, no. 5, pp. 1273-1278, 2013.

[52] G. D. Steinberg, B. S. Carter, T. H. Beaty, B. Childs, and P. C. Walsh, "Family history and the risk of prostate cancer," Prostate, vol. 17, no. 4, pp. 337-347, 1990.

[53] A. S. Whittemore, A. H. Wu, L. N. Kolonel et al., "Family history and prostate cancer risk in black, white, and Asian men in the United States and Canada," American Journal of Epidemiology, vol. 141, no. 8, pp. 732-740, 1995.

[54] C. Chao, R. Haque, S. K. Van Den Eeden, B. J. Caan, K.-Y. T. Poon, and V. P. Quinn, "Red wine consumption and risk of prostate cancer: the California men's health study," International Journal of Cancer, vol. 126, no. 1, pp. 171-179, 2010.

[55] S. Rohrmann, J. Linseisen, T. J. Key et al., "Alcohol consumption and the risk for prostate cancer in the european prospective investigation into cancer and nutrition," Cancer Epidemiology, Biomarkers \& Prevention, vol. 17, no. 5, pp. 1282-1287, 2008. 
[56] M. Rota, L. Scotti, F. Turati et al., "Alcohol consumption and prostate cancer risk: a meta-analysis of the dose-risk relation," European Journal of Cancer Prevention, vol. 21, no. 4, pp. 350359, 2012.

[57] M. Barba, S. E. McCann, H. J. Schünemann et al., "Lifetime total and beverage specific-alcohol intake and prostate cancer risk: a case-control study," Nutrition Journal, vol. 3, article 23, 2004.

[58] R. A. Breslow, L. Wideroff, B. I. Graubard et al., "Alcohol and prostate cancer in the NHANES I epidemiologic follow-up study," Annals of Epidemiology, vol. 9, no. 4, pp. 254-261, 1999.

[59] S. H. G. Andersson, T. Cronholm, and J. Sjövall, "Effects of ethanol on the levels of unconjugated and conjugated androgens and estrogens in plasma of men," Journal of Steroid Biochemistry, vol. 24, no. 6, pp. 1193-1198, 1986.

[60] S. E. McGregor, K. S. Courneya, K. A. Kopciuk, C. Tosevski, and C. M. Friedenreich, "Case-control study of lifetime alcohol intake and prostate cancer risk," Cancer Causes and Control, vol. 24, no. 3, pp. 451-461, 2013.

[61] E. A. Platz, M. F. Leitzmann, E. B. Rimm, W. C. Willett, and E. Giovannucci, "Alcohol intake, drinking patterns, and risk of prostate cancer in a Large Prospective Cohort Study," American Journal of Epidemiology, vol. 159, no. 5, pp. 444-453, 2004.

[62] L. K. Dennis, "Meta-analysis for combining relative risks of alcohol consumption and prostate cancer," Prostate, vol. 42, no. 1, pp. 56-66, 2000.

[63] L. A. Plaskon, D. F. Penson, T. L. Vaughan, and J. L. Stanfordz, "Cigarette smoking and risk of prostate cancer in middle-aged men," Cancer Epidemiology Biomarkers and Prevention, vol. 12, no. 7, pp. 604-609, 2003.

[64] A. W. Hsing, J. K. McLaughlin, L. M. Schuman et al., "Diet, tobacco use, and fatal prostate cancer: results from the Lutheran Brotherhood Cohort study," Cancer Research, vol. 50, no. 21, pp. 6836-6840, 1990.

[65] E. Giovannucci, E. B. Rimm, A. Ascherio et al., "Smoking and risk of total and fatal prostate cancer in United States health professionals," Cancer Epidemiology Biomarkers and Prevention, vol. 8, no. 4, part 1, pp. 277-282, 1999.

[66] J. Ye, S. Wang, M. Barger, V. Castranova, and X. Shi, "Activation of androgen response element by cadmium: a potential mechanism for a carcinogenic effect of cadmium in the prostate," Journal of Environmental Pathology, Toxicology and Oncology, vol. 19, no. 3, pp. 275-280, 2000.

[67] W. S. Dai, J. P. Gutai, L. H. Kuller, and J. A. Cauley, "Cigarette smoking and serum sex hormones in men," American Journal of Epidemiology, vol. 128, no. 4, pp. 796-805, 1988. 


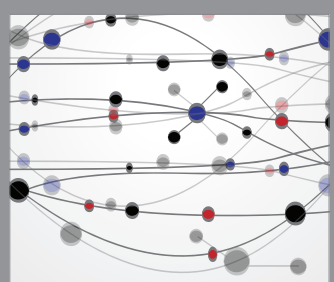

The Scientific World Journal
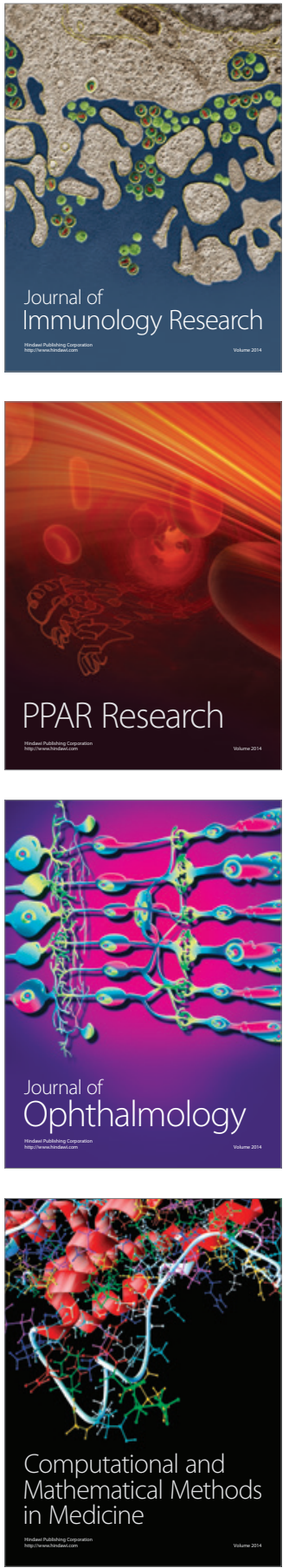

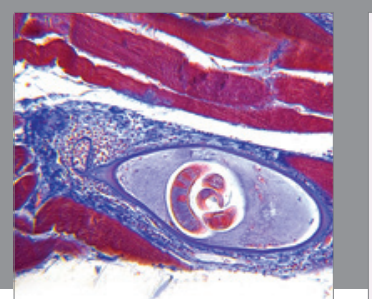

Gastroenterology Research and Practice

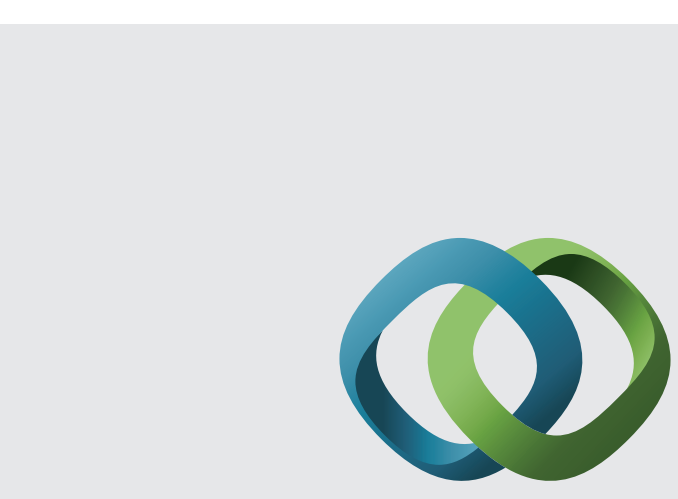

\section{Hindawi}

Submit your manuscripts at

http://www.hindawi.com
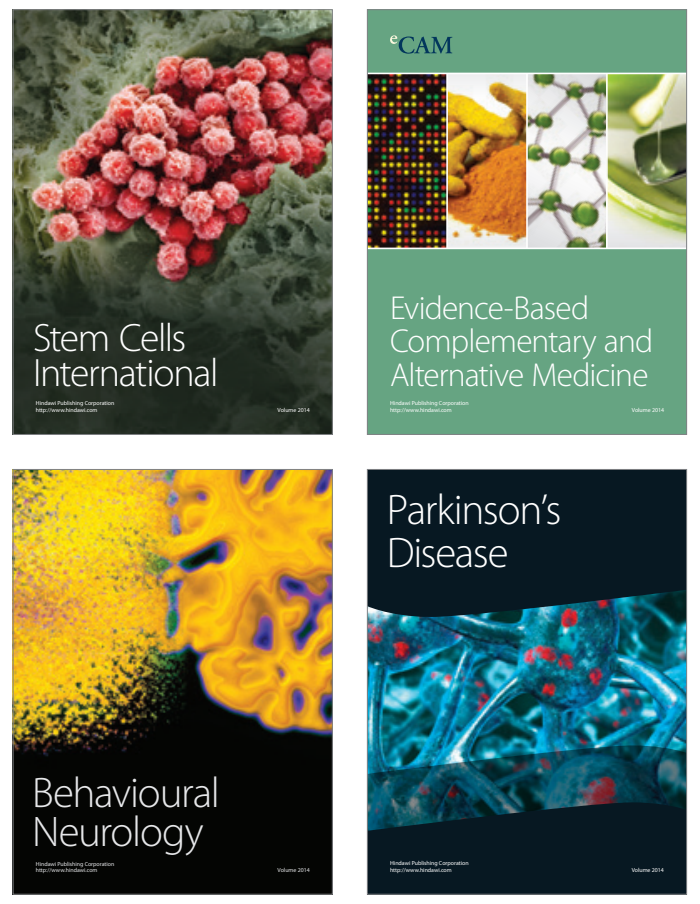
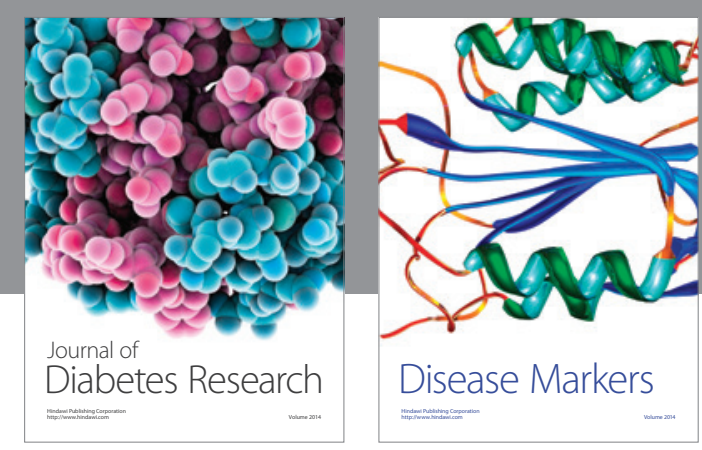

Disease Markers
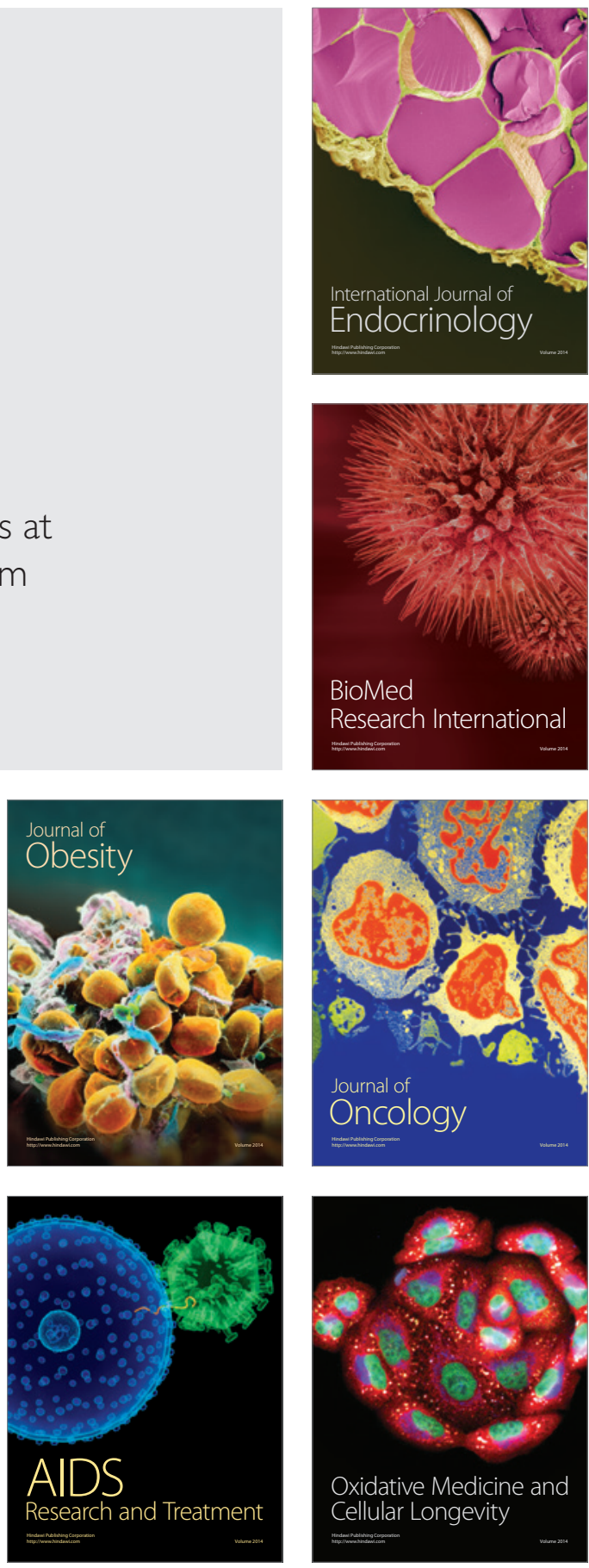